\title{
Store-Operated Calcium Channels as Drug Target in Gastroesophageal Cancers
}

OPEN ACCESS

Edited by:

Fanfan Zhou,

The University of Sydney, Australia

Reviewed by:

Zhe-Sheng Chen,

St. John's University, United States

Zhi Shi,

Jinan University, China

Jonathan Soboloff,

Temple University, United States

*Correspondence:

Zui Pan

zui.pan@uta.edu

Specialty section:

This article was submitted to Pharmacology of Anti-Cancer Drugs,

a section of the journal

Frontiers in Pharmacology

Received: 17 February 2021

Accepted: 12 April 2021

Published: 03 May 2021

Citation:

Chang Y, Roy S and Pan Z (2021) Store-Operated Calcium Channels as

Drug Target in

Gastroesophageal Cancers.

Front. Pharmacol. 12:668730.

doi: 10.3389/fphar.2021.668730

\author{
Yan Chang ${ }^{1}$, Souvik Roy ${ }^{2}$ and Zui Pan ${ }^{1 *}$ \\ ${ }^{1}$ College of Nursing and Health Innovation, The University of Texas at Arlington, Arlington, TX, United States, ${ }^{2}$ Department of \\ Mathematics, The University of Texas at Arlington, Arlington, TX, United States
}

Gastroesophageal cancers, including tumors occurring in esophagus and stomach, usually have poor prognosis and lack effective chemotherapeutic drugs for treatment. The association between dysregulated store-operated calcium entry (SOCE), a key intracellular $\mathrm{Ca}^{2+}$ signaling pathway and gastroesophageal cancers are emerging. This review summarizes the recent advances in understanding the contribution of SOCEmediated intracellular $\mathrm{Ca}^{2+}$ signaling to gastroesophageal cancers. It assesses the pathophysiological role of each component in SOCE machinery, such as Orais and STIMs in the cancer cell proliferation, migration, and invasion as well as stemness maintenance. Lastly, it discusses efforts towards development of more specific and potent SOCE inhibitors, which may be a new set of chemotherapeutic drugs appearing at the horizon, to provide either targeted therapy or adjuvant treatment to overcome drug resistance for gastroesophageal cancers.

Keywords: orai, esophageal squamous cell carcinoma, drug resistance, cancer stem cells, calcium signaling

\section{INTRODUCTION}

\section{Gastroesophageal Cancers}

Gastroesophageal (GE) cancers are malignancies that occur in upper gastrointestinal track, including esophageal, gastric and gastroesophageal junction, and are usually presented with poor prognosis (Hsu et al., 2020). Gastric carcinoma (GC) is the fourth leading cause of death of all cancers in the world with $5^{\circ}$ year survival rate of 10-30\% (Jemal et al., 2011; Sung et al., 2021). For esophageal cancer (EC), the numbers of new case and death in 2020 were 604,000 and 544,000, respectively (Sung et al., 2021). EC is the sixth leading cause of cancer death with $5^{\circ}$ year survival rate less than $20 \%$ (Zhang and Pan, 2020).

Abbreviations: ALDH, aldehyde dehydrogenase; CCE, capacitative Ca2+ entry; CRAC, Ca2+ release-activated Ca2+; CSC cancer stem cells; CT, computerized tomography; EAC, esophageal adenocarcinoma; EC, esophageal cancer; EGFR, epidermal growth factor receptor; EMT, epithelial-mesenchymal transition; ER, endoplasmic reticulum; ESCC, esophageal squamous cell carcinoma; EUS, endoscopic ultrasound; 5-FU, 5-fluorouracil; GC, gastric carcinoma; GE, Gastroesophageal; HIF-1a, hypoxiainducible factor-1 alpha; IP3, inositol 1,4,5-trisphosphate; ITGA7, Integrin $\alpha 7$; LPS, lipopolysaccharide; mAb, monoclonal antibody; MCU, mitochondrial Ca2+ uniporter; PET, positron emission tomography; PM, plasma membrane; RTK, receptor tyrosine kinases; SERCA, ER/SR Ca2+-ATPase; SOCE, store-operated calcium entry; SR, sarcoplasmic reticulum; TKI, tyrosine kinase inhibitor; TRP, transient receptor potential channel; vEGFR-2, vascular endothelial growth factor receptor-2 
Histologic classification identifies two major types of GC: intestinal and diffuse types (Lauren 1965). The intestinal type of GC is believed to be affected by environmental factors such as H. pylori infection in old ages (Warren et al., 1983; Zhang and Pan, 2020). The diffuse type is highly associated with EpsteinBarr virus (EBV) infection and specific genetic alterations such as CDH1 in young ages (Henson et al., 2004). Other factors also contribute to GC that include smoking (Ladeiras-Lopes et al., 2008), alcohol consuming (Jedrychowski et al., 1986) and obesity (Vaughan et al., 1995). EC histologically also has two most common types, i.e. esophageal adenocarcinoma (EAC) and esophageal squamous cell carcinoma (ESCC). ESCC arises from the lining epithelial cells in the upper part of esophagus; and EAC arises from glandular cells present in the lower third of the esophagus, often occurring at transformed Barrett's esophagus (di Pietro et al., 2018; Wheeler and Reed, 2012). The risk factors for ESCC include alcohol consumption (Brooks et al., 2009), smoking (Morita et al., 1994), dietary zinc deficiency (Choi et al., 2018), and mechanical insults (Lambert and Hainaut, 2007).

\section{Current Treatment for Gastroesophageal Cancers}

Symptoms of GE include dyspepsia, early satiety, pain, and symptoms of anemia (Sehdev and Catenacci, 2013). Besides biopsy pathology evaluation, endoscopic ultrasound and computerized tomography (CT) scan or positron emission tomography (PET) scan of chest, abdomen, and pelvis are employed in the diagnosis of GE cancer. Surgery, radiotherapy and chemotherapy are the main treatments for GE cancers. The current chemotherapy drugs include cisplatin, 5-fluorouracil (5FU), paclitaxel, or the combination (Jin et al., 2004). The standard curative intent treatment for both ESCC and EAC is 5-6 weeks of neoadjuvant chemoradiation (CROSS), a combination of paclitaxel and carboplatin with a cumulative radiation dose of 41.4 Gy over 23 fractions followed by esophagectomy (van Heijl et al., 2008). Of course, these standard treatments lead to permanent damage to organs, significant side effects and impede life quality of patients that recover from GE cancers.

\section{Targeted Therapy for Gastroesophageal Cancers}

Targeting therapy has been attracted attention in past few years for its benefit of less side-effects than conventional treatment. Targeting epidermal growth factor receptor (EGFR) family of receptor tyrosine kinases (RTKs) have been approved as a successful approach for lung, breast and other cancers. EGFR/ RTK has four members including EGFR (HER1), HER2, HER3, and HER4. EGFR is a $170 \mathrm{kDa}$ transmembrane receptor on cell membrane. Upon activation, EGFR triggers activation of MAPK, STAT5, and Ras-Raf-MEK pathways resulting in a cascade signaling of cell proliferation and survival (Yano et al., 2003). As a matter of fact, EGFR/HER signaling pathways regulate almost all aspects in cancer biology including cell growth, survival, adhesion, migration, and differentiation. Different from mutant forms in lung cancer and breast cancer, EGFR often presents high copy number and its expression is correlate with advanced stage, poorly differentiated histology, vascular invasion, and poor survival rate in GC and EC (Ku and Ilson, 2013; Wang et al., 2016) (Terashima et al., 2012). Additionally, HER2 is often overexpressed together with EGFR in a significant amount of EC patients as well.

Inhibiting EGFR/RTKs pathways can be achieved either by monoclonal antibody (mAb) or downstream by tyrosine kinase inhibitor (TKI). Several mAbs and more than 20 TKIs have been approved by FDA. For example, cetuximab and panitumumab specifically bind EGFR and trastuzumab and pertuzumab target HER2. Afatinib is a pan-HER family TKI, but selectively and irreversibly inhibits EGFR, HER2, and HER4, and blocks transphosphorylation of HER3. While many of these mAbs and TKIs have been approved by FDA for treatment of lung, colon, breast, or head and neck cancers, their therapeutic benefits for EC are still unclear (Jiao et al., 2018). For example, trastuzumab, a monoclonal antibody against HER2, is the only FDA approved EGFR targeting treatment for EC but has limited response rate (Kurokawa et al., 2014; Doi et al., 2017; Yang et al., 2020). It has been used in combination with 5-FU or cisplatin for HER2 positive GC (Bang et al., 2010). Ramucirumab, a monoclonal antibody of vascular endothelial growth factor receptor-2 (vEGFR-2), was used with paclitaxel together in GC treatment (Wilke et al., 2014). Other agents such as afatinib and bevacizumab, are still in clinical trials (Spicer et al., 2017). Despite the high expectation of TKIs in GC and EC therapy, many clinical trials of TKIs either alone or combined with other therapies have produced disappointing results to date (Wang et al., 2016) and the 5 year survival rate of EC patients is still below 20\% (Siegel et al., 2017). No clinical benefit has been harvested in phase III trials with cetuximab (EXPAND), panitumumab (REAL3), and gefitinib (COG) (Maron et al., 2020). In EXPAND, capecitabine and cisplatin, with or without cetuximab, are used for patients with previously untreated advanced gastric cancer (Lordick et al., 2013). In REAL3, epirubicin, oxaliplatin, and capecitabine, with or without panitumumab, are used in patients with previously untreated advanced GE cancer (Waddell et al., 2013). In COG, gefitinib has been evaluated in esophageal cancer patients after chemotherapy (Dutton et al., 2014).

The failure in all above mentioned Phase III trials for GE cancer patients suggests that new targeted therapies, either alone or combined with inhibiting EGFR/RTK, should be considered. In this review, we intent to discuss an emerging new drug target, known as the store-operated $\mathrm{Ca}^{2+}$ entry (SOCE), which is a key intracellular $\mathrm{Ca}^{2+}$ signaling pathway in GE cancers. We will summarize the recent advances in understanding pathophysiological role of each component of the SOCE machinery in GE cancer cell proliferation, migration, and invasion, as well as stemness maintenance. Lastly, we will discuss efforts towards development of more specific and potent SOCE inhibitors, which appear to be a new set of chemotherapeutic drugs appearing at the horizon to provide either targeted therapy or adjuvant treatment to overcome drug resistant in GE cancers. 


\section{DYSREGULATED INTRACELLULAR CA $^{2+}$ SIGNALING IN CANCER CELLS}

$\mathrm{Ca}^{2+}$ is a vital second messenger in the cells and controls multiple cellular processes including cell growth, cell migration, cell death, cell cycle, autophagy and downstream genes transcription (Cui et al., 2017). Thus, it is not a surprise that $\mathrm{Ca}^{2+}$ homeostasis is a key factor in the tumor initiation, angiogenesis, progression and metastasis (Chen et al., 2011; Chen et al., 2013a; Bergmeier et al., 2013; Yang et al., 2013). The intracellular $\mathrm{Ca}^{2+}$ signaling is known as a complicated network composing of different $\mathrm{Ca}^{2+}$ movements, such as $\mathrm{Ca}^{2+}$ spikes (Baudouin-Legros et al., 2003), waves and oscillations (Ronde et al., 2000; Giannone et al., 2002; Lewis, 2003). They are spatially temporally orchestrated with many channels and transporters playing in the show. First, inositol 1, 4, 5-trisphosphate $\left(\mathrm{IP}_{3}\right)$ receptor or ryanodine receptor (RyR) mediates $\mathrm{Ca}^{2+}$ stores such as endoplasmic/sarcoplasmic reticulum (ER/SR) (Mikoshiba et al., 1994). Secondly, ER/SR Ca ${ }^{2+}$-ATPase (SERCA) pumps $\mathrm{Ca}^{2+}$ from cytosol back to ER/SR. Plasma membrane (PM) $\mathrm{Ca}^{2+}$-ATPase drives $\mathrm{Ca}^{2+}$ from cytosol to extracellular space (Santulli and Marks, 2015). Thirdly, mitochondrial $\mathrm{Ca}^{2+}$ uniporter (MCU) controls mitochondrial $\mathrm{Ca}^{2+}$ uptakes. Fourthly, $\mathrm{PM} \mathrm{Ca}{ }^{2+}$ channels or transporters mediate $\mathrm{Ca}^{2+}$ influx from extracellular space into cytosol, which include voltage-gated $\mathrm{Ca}^{2+}$ channel, transient receptor potential channel (TRP), SOCE channel, $\mathrm{Na}^{+} / \mathrm{Ca}^{2+}$ exchanger (NCX) and purinergic receptor, etc. Since these $\mathrm{Ca}^{2+}$ channels or transporters contain extracellular domains as good drug targets, they received great attention for chemotherapy researchers. Among them, SOCE channel has been actively investigated.

\section{STORE-OPERATED CALCIUM ENTRY MACHINERY}

SOCE was first reported about three decades ago in the name of capacitative $\mathrm{Ca}^{2+}$ entry (CCE) (Putney, 1986). In this pathway, activation of the G-protein coupled receptor (GPCR) leads to the stimulation of PLC to generate $\mathrm{IP}_{3}$, which in turn causes intracellular $\mathrm{Ca}^{2+}$ release, followed by a reduction of $\mathrm{Ca}^{2+}$ concentration inside the ER lumen. The reduced ER $\mathrm{Ca}^{2+}$ store sends a signal to the PM to activate CCE, allowing refill of the reduced ER $\mathrm{Ca}^{2+}$ store (Ma and Pan, 2003; Pan et al., 2014; Pan and Ma, 2015; Cui et al., 2017). This ER $\mathrm{Ca}^{2+}$ storedependent $\mathrm{Ca}^{2+}$ influx is also known as $\mathrm{Ca}^{2+}$ release-activated $\mathrm{Ca}^{2+}$ (CRAC) current. The identification of SOCE machinery has been a long journey and hitherto, a consensus view is that SOCE machinery is complex with various tissue and cell specific components.

\section{Orai and STIM Molecules}

The two main group members in SOCE machinery in mammalian cells are stromal-interacting molecule (STIM1 and STIM2) and Orai (Orai1, Orai2, and Orai3) molecules (Bergmeier et al., 2013). STIM1 and Orail were the first ones to be identified and have been well studied (Yang et al., 2009). STIM1 is an ER transmembrane protein with a luminal EF-hand which could detect changes in the $\mathrm{ER} \mathrm{Ca}^{2+}$ content (Roos et al., 2005; Zhang et al., 2005; Luik et al., 2006; Mercer et al., 2006). Orail locates at PM and constitutes the pore forming unit of the SOCE channel (Yeromin et al., 2006). Upon ER $\mathrm{Ca}^{2+}$ store depletion in physiological or pathological cases, STIM1 molecules are active and translocate to the ER/PM junctional region (Ong et al., 2007). Then, they conjugate with Orai and, subsequently, activate to allow extracellular $\mathrm{Ca}^{2+}$ influx into the cytosol [39] (Ma and Pan, 2003; Huang et al., 2006; Soboloff et al., 2006; Spassova et al., 2006; Vig et al., 2006). Both Orail and STIM1 are ubiquitously expressed in almost all type of cells, including gastric and esophageal epithelial cells with important cellular functions. For example, SOCE mediated $\mathrm{Ca}^{2+}$ influx have been shown to be required for gastric epithelial renewal and repair (Kokoska et al., 1998; Engevik et al., 2020). Our studies demonstrated both STIM1 and Orail are expressed in esophageal epithelial cells and control cell proliferation (Zhu et al., 2014a; Choi et al., 2018) and eotaxin-3 secretion (Odiase et al., 2021).

\section{Transient Receptor Potential Canonical Molecules}

Besides Orai and STIM molecules, transient receptor potential canonical (TRPC) family of $\mathrm{Ca}^{2+}$ permeable channels are also involved in the SOCE pathway. TRPC channels are tetrameric molecules with six transmembrane domains on each subunit and located on PM. In human cells, there are 6 TRPC channels divided into 2 families according to their biological functions: 1) TRPC1, TRPC4, TRPC5; 2) TRPC3, TRPC6, TRPC7 (Zhu et al., 1995). Their activation results from the stimuli induced PIP2 hydrolysis (Venkatachalam and Montell, 2007). TRPCs appear to interactive with other proteins, such as caveolin, junctate, and junctophilin (Ong and Ambudkar, 2015). The interaction with caveolin helps TRPC3 to be recruited to a channel complex within ER/PM junctions and form a functional signaling complex (Adebiyi et al., 2011). TRPCs may even indirectly interact with Orai in ER/PM complex with the requirement of STIM1 (Choi et al., 2014). While not all the TRPCs are involved in the SOCE signaling, TRPC1 and TRPC4 are clearly documented to mediate SOCE. TRPC1 was identified to be the first of the TRPC channels that was involved in SOCE in mammalian cells (Liu et al., 2003). It has been reported that TRPC1 mediates SOCE in secretory cells (Hong et al., 2011), vascular endothelial cells (Ma et al., 2011), smooth muscle cells (Dietrich et al., 2006), and endothelial cells (Tiruppathi et al., 2006). TRPC4-mediated SOCE is demonstrated in mouse mesangial cells (Wang et al., 2004), human adrenal cells (Philipp et al., 2000), both mouse and human endothelial cells (Sundivakkam et al., 2012), human gingival keratinocytes (Fatherazi et al., 2007), human corneal epithelial cells (Yang et al., 2005) and human pulmonary artery smooth muscle cells (Zhang et al., 2004). TRPC 3 may mediate SOCE depending on cell type and expression level (Kim et al., 2009). TRPC6-mediated SOCE has been well studied in breast cancer cells (Guilbert et al., 2008; Jardin et al., 2018; Jardin et al., 2020). 


\section{Store-Operated Calcium Entry in Gastroesophageal Cancers}

Alteration in SOCE has been observed in many diseases. While genetic mutations in Orail or STIM1 were found in immune disorders, skeletal muscle myopathy and heart hypertrophy (Feske, 2011; Le Deist and Capiod, 2011; Verbsky and Chatila, 2011; Berna-Erro et al., 2012; Fuchs et al., 2012; Shaw and Feske, 2012), changes in expression and/or channel complex components are more commonly reported in various types of malignant, including GE cancers.

We previously reported upregulated expression of Orail in tumor tissues compared to that in adjacent non-tumorous tissues in ESCC patients (Zhu et al., 2014a). The high expression of Orail is associated with poor disease-free and overall survival rates. Both gene manipulation and pharmacologic studies demonstrated that elevated Orail results in hyperactivity of intracellular $\mathrm{Ca}^{2+}$ oscillations and, thus, controls rampant cell proliferation in ESCC cells. Interestingly, an essential trace mineral nutrient zinc is able to inhibit Orail-mediated SOCE in ESCC cells, which has been linked to its cancer prevention function (Choi et al., 2018).

Enhanced SOCE and overexpression of Orail and STIM1 have been found in GC as well (Kokoska et al., 1998; Wong et al., 2017). STIM1 can promote gastric cancer progression (Xu et al., 2016) and silencing STIM1 inhibits cell proliferation via arrest of the cell cycle at the G0/G1 phase and increases cell apoptosis in vitro (Liu et al., 2015). From a study with more than 300 GC patients, $\mathrm{Xia}$, et al reported that Orail and STIM1 expressions were higher in GC tissues compared with adjacent non-tumor tissues (Xia et al., 2016). Similar to the study in ESCC, they also found that higher Orail and/or STIM1 expression is associated with more advanced stages and poor prognosis. Moreover, Wong, et al showed that lipopolysaccharide (LPS) stimulates SOCE and results in the activation of downstream NF- $\kappa \mathrm{B}$ signaling pathway. It is well known that LPS is an enriched component of the outer membrane of gram-negative bacteria $H$. pylori, which is a major risk factor for GC and triggers chronic inflammation responses (Zhang and Pan, 2020). SOCE-activated nuclear translocation of NF- $\kappa \mathrm{B}$ then increases the transcription and expression of cyclooxygenase-2, a major inflammatory gene (Wang et al., 2017a). On the other hand, suppressing Orail and STIM1 expression by a $\mathrm{Ca}^{2+}$-binding protein S100A14 has been shown to induce cell differentiation and inhibit cell metastasis in GC (Zhu et al., 2017).

The role of TRPC-mediated SOCE in GE cancers has been studied best on TRPC6. Similar to Orail, TRPC6 is also overexpressed in ESCC tumor tissues compared with normal esophageal tissues in terms of both mRNA and protein levels and its high expression is associated with poor prognosis (Zhang et al., 2013). Shi, et al, demonstrated that TRPC6 is a key factor to control G2 phase transition in tumorigenesis of EC (Shi et al., 2009). Due to the important role of TRPC6-mediated $\mathrm{Ca}^{2+}$ signaling, it is not surprising to see that the inhibition of TRPC6 leads to cell cycle arrest via Cdk1 in ESCC cells and decreased tumor formation in a mouse xenograft ESCC model (Ding et al., 2010; Zhang et al., 2013). In GC epithelial cells, the
TRPC6 has been shown to be upregulated on protein and mRNA level and was responsible for regulation of the cell cycle, as the inhibition of TRPC6 resulted in cell cycle arrest in the G2/M phase and inhibited cell growth (Cai et al., 2009). Moreover, treatment of xenografted GC nude mice with a TRPC6 blocker resulted in the inhibition of the development of tumor. The TRPC6 may form a channel complex with TRPC1 and TRPC3 to fulfill their function, which was demonstrated in a study on TGF$\beta 1$-induced epithelial-mesenchymal transition (EMT) in GC cells (Ge et al., 2018). The authors showed that TRPC1/3/6 complex mediates $\mathrm{Ca}^{2+}$ influx and actives downstream the Ras/Raf1/ERK signaling pathway and the inhibition of TRPC1/3/6 impedes TGF- $\beta 1$-induced EMT. Using a newly developed potent TRPC6 antagonist, a separate study also showed that inhibition of this $\mathrm{Ca}^{2+}$ channel suppresses proliferation of several GC cell lines as well as GC tumor growth in a xenograft model (Ding et al., 2018).

\section{TARGETING STORE-OPERATED CALCIUM ENTRY CHANNELS FOR NEW CHEMOTHERAPY DRUGS IN GASTROESOPHAGEAL CANCERS}

\section{Store-Operated Calcium Entry Inhibitors}

Since SOCE-mediated $\mathrm{Ca}^{2+}$ signaling pathways are associated with several hallmarks of cancer, targeting SOCE turns out to be an active area in chemotherapy drug development area. As a result, many SOCE inhibitors have been reported to have anticancer potential. In Table 1, we present a summary of these SOCE inhibitors, which may not be comprehensive, due to the swift advancement of this field. The earliest SOCE blocker to be used is SKF-96365, which was shown to inhibit cancer cell migration and tumor metastasis in breast (Yang et al., 2009) and cervical cancers (Chen et al., 2011). It was also used in our early work in ESCC and was demonstrated to decrease Orail-mediated SOCE and to reduce tumor growth in vivo (Zhu et al., 2014a). 2-APB is another effective SOCE inhibitor with low selectivity. For this purpose, it was first reported as antagonist for $\mathrm{IP}_{3}$ receptor with much higher IC50 (Yamashita et al., 2011). It can reduce cell proliferation and tumorigenesis in gastric cancer and colorectal cancer progression (Sakakura et al., 2003) (Wang et al., 2015). ML-9, an inhibitor for myosin light-chain kinase (MLCK) and STIM1 puncta, can promote cell death and autophagy in prostate cancer (Kondratskyi et al., 2014). RO2959, a novel, potent and selective SOCE inhibitor, inhibits gene expression, cytokine production, and proliferation in $\mathrm{T}$ cells (Chen et al., 2013a). SB01990, SPB06836, KM06293 and RH01882 are a cluster of SOCE inhibitors targeting and altering the $\mathrm{Ca}^{2+}$ selectivity filter of Orail (Sampath and Sankaranarayanan, 2016). GSK-5503A and GSK-7975A are Orail-and Orai3-mediated SOCE inhibitors that slowly affect SOCE currents with no effect on STIM1-Orail coupling (Derler et al., 2013). Furthermore, the compounds also suppress TRPV6 channels, which is possibly because they share the target site (Jairaman and Prakriya, 2013). BTP2 or YM-58483 is a potent inhibitor for both CRAC and TRPC-mediated SOCE 
TABLE 1 | Store-operated calcium entry inhibitors.

\begin{tabular}{|c|c|c|c|c|}
\hline Drug & Disease & Target & Clinical trial & References \\
\hline SKF-96365 & $\begin{array}{l}\text { Breast cancer, cervical cancer, } \\
\text { ESCC }\end{array}$ & $\begin{array}{l}\text { TRPC, TRPV4, } \\
\text { Orai1-STIM1 }\end{array}$ & & $\begin{array}{l}\text { Yang et al. (2009), Chen et al. } \\
\text { (2011) }\end{array}$ \\
\hline 2-APB & Gastric cancer, colorectal cancer & $\begin{array}{l}\text { Orai1, TRPV2, } \\
\text { IP3R1 }\end{array}$ & & $\begin{array}{l}\text { Yamashita et al. (2011), } \\
\text { Sakakura et al. (2003) }\end{array}$ \\
\hline ML-9 & Prostate cancer & STIM1 puncta & & Kondratskyi et al. (2014) \\
\hline RO2959 & $\begin{array}{l}\text { Inhibition on cytokine production } \\
\text { and } T \text { cell proliferation }\end{array}$ & $\begin{array}{l}\text { IP3-dependent } \\
\text { CRAC } \\
\text { Orai1 }\end{array}$ & & Chen et al. (2013b) \\
\hline $\begin{array}{l}\text { SB01990, SPB06836, } \\
\text { KM06293, RH01882 }\end{array}$ & - & Orai1 & & $\begin{array}{l}\text { Sampath and } \\
\text { Sankaranarayanan (2016) }\end{array}$ \\
\hline GSK-5503A, GSK-7975A & - & Orai1 & & $\begin{array}{l}\text { Derler et al. (2013), Jairaman } \\
\text { and Prakriya (2013) }\end{array}$ \\
\hline BTP2/YM-58483 & $\begin{array}{l}\text { Antigen-induced airway } \\
\text { inflammation }\end{array}$ & CRAC, TRPV4 & & $\begin{array}{l}\text { He et al. (2005), Yoshino et al. } \\
\text { (2007) }\end{array}$ \\
\hline Carboxyamidotriazole & Ovarian cancer & CRAC & $\begin{array}{l}\text { NCT00006486 (Phase 2, completed, metastatic } \\
\text { kidney cancer) } \\
\text { NCT00003249 (Phase 1, completed, advanced } \\
\text { cancers) } \\
\text { NCT00003869 (Phase 3, completed, Stage III or } \\
\text { IV non-small cell lung cancer) } \\
\text { NCT00019461 (Phase 2, completed, Fallopian } \\
\text { Tube cancer, ovarian cancer, primary peritoneal } \\
\text { cavity cancer) } \\
\text { NCT00019019 (Phase 1, completed, advanced } \\
\text { solid tumors or refractory Lymphomas) } \\
\text { NCT00005045 (Phase 2, completed, advanced } \\
\text { kidney cancer) } \\
\text { NCT00004146 (Phase 2, completed, newly } \\
\text { diagnosed supratentorial glioblastoma) }\end{array}$ & Kohn et al. (2001) \\
\hline CM2489, СM3457, CM4620 & $\begin{array}{l}\text { plaque psoriasis, acute } \\
\text { pancreatitis, sever COVID-19 } \\
\text { pneumonia }\end{array}$ & CRAC & $\begin{array}{l}\text { NCT04195347 (Phase1/2, recruiting, Acute } \\
\text { Pancreatitis) } \\
\text { NCT03709342 (Phase 2, completed, acute } \\
\text { pancreatitis) } \\
\text { NCT04661540 (Phase 2, recruiting, in critical } \\
\text { COVID-19 pneumonia) } \\
\text { NCT04681066 (Phase 2, recruiting, acute } \\
\text { pancreatitis and accompanying SIRS) } \\
\text { NCT03401190 (Phase 2, completed, acute } \\
\text { pancreatitis and SIRS) } \\
\text { NCT04345614 (Phase 2, recruiting, severe } \\
\text { COVID-19 pneumonia) }\end{array}$ & $\begin{array}{l}\text { Ramos et al. (2012), Waldron } \\
\text { et al. (2019) }\end{array}$ \\
\hline Pyr2, 3, 6, and 10 & Breast cancer & Orai1, TRPC3 & & Schleifer et al. (2012) \\
\hline RP4010 & $\begin{array}{l}\text { ESCC and pancreatic ductal } \\
\text { adenocarcinoma }\end{array}$ & Orai1 & $\begin{array}{l}\text { NCT03119467 (Phase 1, concluded, relapsed or } \\
\text { refractory lymphomas) }\end{array}$ & $\begin{array}{l}\text { Cui et al. (2018), Khan et al. } \\
\text { (2020) }\end{array}$ \\
\hline
\end{tabular}

(He et al., 2005) (Yoshino et al., 2007). However, the mode of action may be more than direct channel antagonist. A report showed that BTP-2 can depolarize the cell membrane via TRPM4 activation and, thus contribute to the inhibition of SOCE and cytokine release (Takezawa et al., 2006). Carboxyamidotriazole, a non-selective SOCE inhibitor in non-excitable cell, has been approved to test its anti-tumor effects in Phase I and Phase II clinical trials for several cancers (Kohn et al., 2001) (Table 1). CM2489, CM3457 and CM4620 are three more selective SOCE inhibitors, which have been shown to prevent $\mathrm{Ca}^{2+}$ entry, and, thus, are used either to treat moderate-to-severe plaque psoriasis, or to reduce acute pancreatitis severity, or to inhibit lymphocytes and $\mathrm{T}$ cell-derived cytokine production (Ramos et al., 2012; Waldron et al., 2019) (Table 1). The Pyrazole analogs, including Pyr2, 3, 6 and 10, show different selectivity on
TRPC3 and Orail-mediated SOCE. Pyr10 is potent and selective for TRPC3-mediated SOCE. Pyr6 is potent to Orai1mediated SOCE, while Pyr3 equally inhibits both channels (Schleifer et al., 2012).

Among the above mentioned selective SOCE inhibitors, only two have been used in clinical trials but none for cancer treatment. CM2489 and CM 4620 from CalciMedica are used to block the production and release of pro-inflammatory cytokines from immune cells, and they are used in clinical trials for the treatment of plaque psoriasis and pancreatitis (Ramos et al., 2012; Waldron et al., 2019). During this pandemic, CM 4620 has also been evaluated in a new clinical trial for treatment of severe COVID-19 pneumonia (Table 1). With improved selectivity and reduced toxicity, modified forms of these SOCE channel inhibitors may still hold promise for 
further cancer therapeutic drug development. One of such compound will be discussed in great detail below.

\section{RP4010 in Gastroesophageal Cancer}

RP4010 from Rhizen Pharmaceuticals is another selective SOCE channel inhibitor. Due to its low toxicity and high solubility, it has been successfully used in clinical trial in the form of an oral medicine. It was studied in a Phase I/Ib study for patients with relapsed or refractory non-Hodgkin's lymphoma (NCT03119467). Additionally, its anti-cancer effects have been reported in both ESCC and pancreatic ductal adenocarcinoma (Cui et al., 2018; Khan et al., 2020).

Compared with other reported SOCE channel inhibitors, RP4010 is more potent in blocking SOCE in ESCC cells (Cui et al., 2018). In MTT assay, the IC50 of RP4010 is estimated about $1 \mu \mathrm{M}$ for most tested ESCC cell lines whereas the $\mathrm{IC}_{50}$ of BTP- 2 is $17 \mu \mathrm{M}$ as best. Our studies showed that treatment of RP4010 resulted in reduction of intracellular $\mathrm{Ca}^{2+}$ oscillations, and caused cell cycle arrest at G0/G1 phase in several cultured human ESCC cell lines. This inhibitory effect on cell proliferation is caused due to decreasing nuclear translocation of nuclear factor kappa $\mathrm{B}$ (NF-kB). Moreover, it dramatically inhibits tumor growth in xenograft ESCC nude mice without observable adverse side effect, evidenced by normal histology results in all vital organs. Therefore, it remains to be a promising chemotherapy drug for GE cancers. Further, mechanistic study on the exact inhibitory effect on SOCE machinery and continue clinical evaluation are warranted.

\section{TARGETING STORE-OPERATED CALCIUM ENTRY IN GASTROESOPHAGEAL CANCER DRUG RESISTANCE}

\section{Store-Operated Calcium Entry and Drug Resistance}

Drug resistance is responsible for relapses of cancers and remains to be a big challenge in most cancer treatment. It includes resistance to classical chemotherapeutic agents or targeted therapies; it can occur at treatment (intrinsic) or is acquired after therapy. Accumulating evidence suggests that SOCE plays a significant role in drug resistance. The expression of Orail and STIM1 as well as SOCE are enhanced in therapy resistant ovary cancer cells (Schmidt et al., 2014). SOCE is required for the anticancer effect of cisplatin, a widely used conventional chemotherapy drug, in non-small cell lung carcinoma (Gualdani et al., 2019). Additional studies also showed that Orail/STIM1-mediated SOCE is involved in 5-fluorouracil (5FU), another widely used conventional chemotherapy drug, or gemcitabine resistance in pancreatic adenocarcinoma (Kondratska et al., 2014) and hepatocellular carcinoma cells (Tang et al., 2017). The proposed mechanisms, underlying the impact of SOCE on chemotherapy resistance, are attributed to inducing $\mathrm{Ca}^{2+}$ overload (Zheng, 2017), autophagy, EMT, activating MAPK and PI3K-Akt/Sgk signaling pathways (Wang et al., 2017a), upregulating transcription factors of NF$\kappa B, c-m y c$, and p53 (Cui et al., 2017). Moreover, SOCE inhibitors decreased chemotherapy resistant cell migration in ovarian cancer (Huang et al., 2020).

\section{$\mathrm{Ca}^{2+}$ Signaling in Cancer Stem Cells}

Cancer stem cells (CSC) are a subpopulation of tumor cells with capabilities of proliferating, self-renewing and differentiating. They are more resistant to chemotherapy drugs or radiation, which often leads to treatment failure and subsequent tumor recurrence (Hamburger and Salmon, 1977) (Bao et al., 2006; Li et al., 2008).

The identification and isolation of stem cells in GE tumors can be achieved by CSC markers using flow cytometry. Like adult stem cells, CSCs express the transcription factors SOX2, OCT-4, NANOG, and detoxification enzyme aldehyde dehydrogenase (ALDH) (Mohiuddin et al., 2020). While some cell surface markers, such as CD44, CD24, and CD133, have been identified as common CSC markers for almost all cancer types (Liu et al., 2006), CSC in GC and EC cancers present their specific markers as well (Takaishi et al., 2009). For example, Ming, et al showed that integrin $\alpha 7$ (ITGA7) is characterized as a functional CSC marker in ESCC (Ming et al., 2016). The known CSC markers in GE cancers are summarized in Table 2.

The stemness of CSC requires their distinct cellular characteristics, which is associated with different intracellular $\mathrm{Ca}^{2+}$ signaling compared with non-stem cancer cells (Cheng et al., 2018). Voltage gated $\mathrm{Ca}^{2+}$ channels (VOC) are a cluster of transmembrane proteins located on the cell membrane, which have been reported to regulate cell proliferation and migration in the cancer cells (Prevarskaya et al., 2018). VOC a2 $\delta 1$ subunit (CACNA2D1) was identified as a CSC marker in diagnosis of hepatocellular carcinoma (Zhao et al., 2013). Data in small-cell lung cancer/non-small cell lung cancer indicates that VOC a $2 \delta 1$ subunit increase the chemotherapy or radiotherapy resistance (Yu et al., 2018) that makes $\alpha 2 \delta 1$ a target for treatment in the clinical setup. Moreover, t-type $\mathrm{Ca}^{2+}$ channel Cav3.2 is upregulated and induces CSC proliferation in glioblastoma (Zhang et al., 2017). This also results in Cav3.2 being a potential target in cancer therapy.

For the ER resident $\mathrm{Ca}^{2+}$ channels, IP3R and RyR are required for CSC stemness and proliferation. In breast cancer, chemotherapy induced cytosolic $\mathrm{Ca}^{2+}$ release from ER via RyR1 causes enrichment of CSC in vivo (Lu et al., 2017). With RyR1 knockdown, the CSCs diminish in the severe combined immunodeficiency (SCID) mice model. IP3R induced- $\mathrm{Ca}^{2+}$ release is required for tumor growth and metastasis in melanoma (Marciel et al., 2018). Pharmacological inhibitors targeting $\mathrm{Ca}^{2+}$ release via IP3R, are employed to block CSC function in the treatment of glioblastoma (Dong et al., 2017).

\section{Store-Operated Calcium Entry in Cancer Stem Cells}

In addition to the VOC and IP3R/RyR, SOCE contributes to the stemness and differentiation of CSC as well (Figure 1). In oral/ oropharyngeal squamous cells, Orail enhances cancer stemness by activation of NFAT pathway (Lee et al., 2016). By interaction with hypoxia-inducible factor-1 alpha (HIF-1a), STIM1 
TABLE 2 | Cancer stem cell markers in gastroesophageal cancers.

Cancer type

Gastric cancer

Esophageal cancer
Markers

ALDH Nishikawa et al. (2013), CD44 Takaishi et al. (2009), CD44v8-10 Lau et al. (2014), CD133 Zhu et al. (2014b), CD24 Fujikuni et al. (2014), CD54 Chen et al. (2012), CD90 Xue et al. (2012), CD49f Fukamachi et al. (2013), CD71 Ohkuma et al. (2012), EpCAM Wenqi et al. (2009)

ITGA7, CD44, ALDH, CD133, CD90 Wang et al. (2017b)

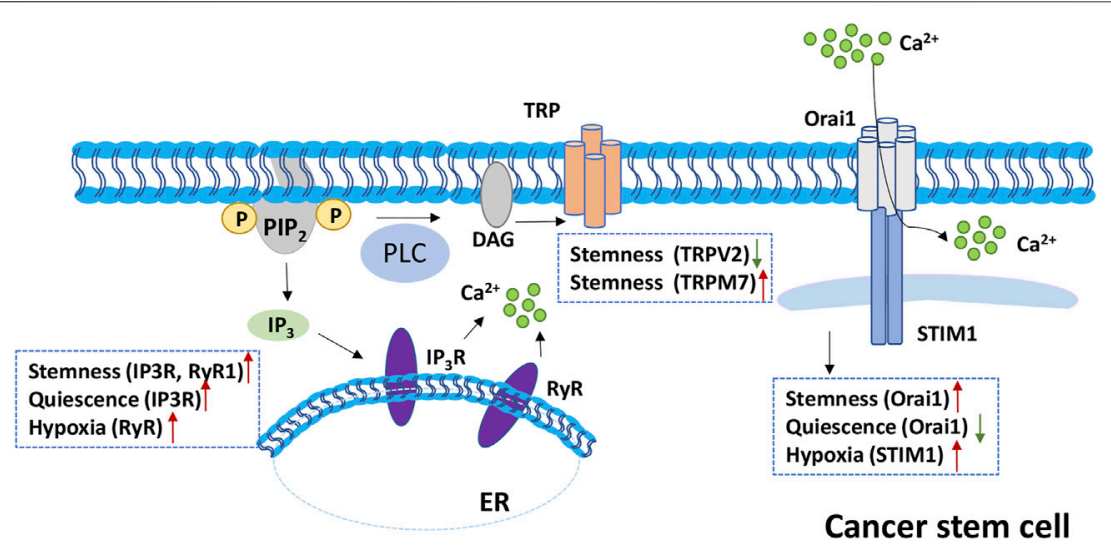

FIGURE 1 |Role of SOCE in cancer stem cell (CSC). Left, IP3R and RyR are Ca ${ }^{2+}$ channels on the ER membrane. Activation of IP3R or RyR channels release Ca ${ }^{2+}$ from ER to cytoplasm. In CSC, IP3R and RyR promote stemness and quiescence. RyR also contributes to the cell hypoxia microenvironment. Middle, TRP family is involved in the stemness maintenance of CSC with negative and positive regulation of TRPV2 and TRPM7 separately. Right, Orai1 is upregulated in CSC assisting stemness maintenance; the downregulation of Orai1 promote quiescence maintenance. While STIM1 positively regulates CSC hypoxia microenvironment.

promotes the hypoxia-induced tumorigenesis in hepatocarcinoma ( $\mathrm{Li}$ et al., 2015). Another study reveals that Orail mediated SOCE are essential for tumor invasion in glioblastoma (Motiani et al., 2013). Furthermore, the treatment of SKF-96365 can reduce CSC cell proliferation and decrease stemness in glioblastoma (Aulestia et al., 2018).

TRP channels may be involved in regulation of CSC function as well. Transient receptor potential melastatin 7 (TRPM7) enhances tumor migration and invasion by up-regulating expression of CSC, ALDH1, and CD133 in glioma cells (Liu et al., 2014). Transient receptor potential vanilloid 2 (TRPV2) is reported to inhibit CSC proliferation and promotes CSC differentiation in glioblastoma (Morelli et al., 2012). Knockdown of TRPV2 promotes colony formation and CSC expression in hepatocellular carcinoma (Hu et al., 2018).

In order to overcome cancer reoccurring issue, many clinical trials have been conducted focusing on elimination of CSC. Mithramycin, a selective inhibitor of transcription factor Sp1, is on phase 1 clinical trial for esophageal neoplasms with the identifier number of NCT01624090. Metformin, a widely used diabetes drug, has been administrated in combination with chemotherapy in several clinical trials to treat multiple cancers, including colon cancer (NCT01440127), ovarian, fallopian tube, and primary peritoneal cancer (NCT01579812). Both drugs may not show huge effects on diminishing the tumor size, but they significantly decrease the recurrence of tumor. Currently, there is no report on whether mithramycin or metformin alter the expression of SOCE, voltage-gated or other $\mathrm{Ca}^{2+}$ channels in gastroesophageal CSC. Regardless the answer, it could be a promising treatment to combine metformin with SOCE inhibitors for a superior anti-cancer effect with reduced drug resistance.

\section{CONCLUSION AND FUTURE DIRECTIONS}

In this review, we summarized the recent studies on the role of SOCE in GE cancers. Apparently, SOCE plays multiple important roles in cancer cells proliferation, migration, invasion, metastasis and stemness maintenance. EGFRtargeting therapy has been used in many other cancers but with limited benefits for GE cancer patients. Since $\mathrm{Ca}^{2+}$ plays a vital role in the EGFR signaling pathway, SOCE-mediated signaling pathway may crosstalk with EGFR pathway. We speculate that combined inhibitors for both SOCE and EGFR pathways could achieve better anti-cancer effects than single agent alone for GE cancer. While the function of SOCE in drug resistant and CSC in GE cancers remains unclear, it is reasonable to foresee that a similar association exist as that in other cancers. Compared with parental cancer cells, the drug resistance GE cancer cells and CSC may contain different SOCE components or ratio, which may present distinct SOCE channel properties. Targeting the SOCE channels, specific and potent SOCE blockers could be used as a new chemotherapy for GE cancers. Moreover, combining SOCE inhibitors with other chemotherapy drugs targeting 
both normal tumor cells and CSC may enhance treatment efficiency and prevent tumor re-occurrences. In the combined treatment, how to synergize the drugs and reduce the drug resistance? How to decrease the side effect of drugs and obtain a better prognosis? Further investigation is required along those lines.

\section{AUTHOR CONTRIBUTIONS}

YC and ZP conceived of the topics. YC wrote the first draft of this manuscript. SR and ZP edited and wrote the final draft of this manuscript.

\section{REFERENCES}

Adebiyi, A., Narayanan, D., and Jaggar, J. H. (2011). Caveolin-1 Assembles Type 1 Inositol 1,4,5-trisphosphate Receptors and Canonical Transient Receptor Potential 3 Channels into a Functional Signaling Complex in Arterial Smooth Muscle Cells. J. Biol. Chem. 286, 4341-4348. doi:10.1074/jbc.m110. 179747

Aulestia, F. J., Néant, I., Dong, J., Haiech, J., Kilhoffer, M. C., Moreau, M., et al. (2018). Quiescence Status of Glioblastoma Stem-like Cells Involves Remodelling of Ca2+ Signalling and Mitochondrial Shape. Sci. Rep. 8, 9731. doi:10.1038/s41598-018-28157-8

Bang, Y. J., Van Cutsem, E., Feyereislova, A., Chung, H. C., Shen, L., Sawaki, A.., et al. (2010). Trastuzumab in Combination with Chemotherapy versus Chemotherapy Alone for Treatment of HER2-Positive Advanced Gastric or Gastro-Oesophageal Junction Cancer (ToGA): a Phase 3, Open-Label, Randomised Controlled Trial. Lancet 376, 687-697. doi:10.1016/s01406736(10)61121-x

Bao, S., Wu, Q., McLendon, R. E., Hao, Y., Shi, Q., Hjelmeland, A. B., et al. (2006). Glioma Stem Cells Promote Radioresistance by Preferential Activation of the DNA Damage Response. Nature 444, 756-760. doi:10.1038/nature05236

Baudouin-Legros, M., Brouillard, F., Tondelier, D., Hinzpeter, A., and Edelman, A. (2003). Effect of Ouabain on CFTR Gene Expression in Human Calu-3 Cells. Am. J. Physiology-Cell Physiol. 284, C620-C626. doi:10.1152/ajpcell.00457.2002

Bergmeier, W., Weidinger, C., Zee, I., and Feske, S. (2013). Emerging Roles of Store-Operated Ca2+entry through STIM and ORAI Proteins in Immunity, Hemostasis and Cancer. Channels 7, 379-391. doi:10.4161/chan.24302

Berna-Erro, A., Woodard, G. E., and Rosado, J. A. (2012). Orais and STIMs: Physiological Mechanisms and Disease. J. Cell. Mol. Med. 16, 407-424. doi:10. 1111/j.1582-4934.2011.01395.x

Brooks, P. J., Enoch, M. A., Goldman, D., Li, T. K., and Yokoyama, A. (2009). The Alcohol Flushing Response: an Unrecognized Risk Factor for Esophageal Cancer from Alcohol Consumption. Plos Med. 6, e50. doi:10.1371/journal. pmed. 1000050

Cai, R., Ding, X., Zhou, K., Shi, Y., Ge, R., Ren, G., et al. (2009). Blockade of TRPC6 Channels Induced G2/M Phase Arrest and Suppressed Growth in Human Gastric Cancer Cells. Int. J. Cancer 125, 2281-2287. doi:10.1002/ijc.24551

Chen, G., Panicker, S., Lau, K.-Y., Apparsundaram, S., Patel, V. A., Chen, S.-L., et al. (2013a). Characterization of a Novel CRAC Inhibitor that Potently Blocks Human T Cell Activation and Effector Functions. Mol. Immunol. 54, 355-367. doi:10.1016/j.molimm.2012.12.011

Chen, T., Yang, K., Yu, J., Meng, W., Yuan, D., Bi, F., et al. (2012). Identification and Expansion of Cancer Stem Cells in Tumor Tissues and Peripheral Blood Derived from Gastric Adenocarcinoma Patients. Cell Res. 22, 248-258. doi:10. 1038/cr.2011.109

Chen, Y.-F., Chiu, W.-T., Chen, Y.-T., Lin, P.-Y., Huang, H.-J., Chou, C.-Y., et al. (2011). Calcium Store Sensor Stromal-Interaction Molecule 1-dependent Signaling Plays an Important Role in Cervical Cancer Growth, Migration, and Angiogenesis. Proc. Natl. Acad. Sci. 108, 15225-15230. doi:10.1073/pnas. 1103315108

Chen, Y.-T., Chen, Y.-F., Chiu, W.-T., Liu, K.-Y., Liu, Y.-L., Chang, J.-Y., et al. (2013b). Microtubule-associated Histone Deacetylase 6 Supports the Calcium

\section{FUNDING}

ZP received NIH grants R01CA185055, S10OD025230, and a University of Texas at Arlington start-up fund. The latter supports the open access publication fee.

\section{ACKNOWLEDGMENTS}

Authors are thankful for the generous support from the UTA College of Nursing \& Health Innovation Bone-Muscle Research Center (https://www.uta.edu/conhi/research/bmrc/index.php).

Store Sensor STIM1 in Mediating Malignant Cell Behaviors. Cancer Res. 73, 4500-4509. doi:10.1158/0008-5472.can-12-4127

Cheng, Q., Chen, A., Du, Q., Liao, Q., Shuai, Z., Chen, C.., et al. (2018). Novel Insights into Ion Channels in Cancer Stem Cells (Review). Int. J. Oncol. 53, 1435-1441. doi:10.3892/ijo.2018.4500

Choi, S., Cui, C., Luo, Y., Kim, S. H., Ko, J. K., Huo, X., et al. (2018). Selective Inhibitory Effects of Zinc on Cell Proliferation in Esophageal Squamous Cell Carcinoma through Orai1. FASEB j. 32, 404-416. doi:10.1096/fj.201700227rrr

Choi, S., Maleth, J., Jha, A., Lee, K. P., Kim, M. S., So, I., et al. (2014). The TRPCsSTIM1-Orai Interaction. Handbook Exp. Pharmacol. 223, 1035-1054. doi:10. 1007/978-3-319-05161-1_13

Cui, C., Chang, Y., Zhang, X., Choi, S., Tran, H., Penmetsa, K. V., et al. (2018). Targeting Orail-Mediated Store-Operated Calcium Entry by RP4010 for Antitumor Activity in Esophagus Squamous Cell Carcinoma. Cancer Lett. 432, 169-179. doi:10.1016/j.canlet.2018.06.006

Cui, C., Merritt, R., Fu, L., and Pan, Z. (2017). Targeting Calcium Signaling in Cancer Therapy. Acta Pharmaceutica Sinica B 7, 3-17. doi:10.1016/j.apsb.2016. 11.001

Derler, I., Schindl, R., Fritsch, R., Heftberger, P., Riedl, M. C., Begg, M., et al. (2013). The Action of Selective CRAC Channel Blockers Is Affected by the Orai Pore Geometry. Cell Calcium 53, 139-151. doi:10.1016/j.ceca.2012.11.005

di Pietro, M., Canto, M. I., and Fitzgerald, R. C. (2018). Endoscopic Management of Early Adenocarcinoma and Squamous Cell Carcinoma of the Esophagus: Screening, Diagnosis, and Therapy. Gastroenterology 154, 421-436. doi:10. 1053/j.gastro.2017.07.041

Dietrich, A., Chubanov, V., Kalwa, H., Rost, B. R., and Gudermann, T.. 2006. Cation Channels of the Transient Receptor Potential Superfamily: Their Role in Physiological and Pathophysiological Processes of Smooth Muscle Cells. Pharmacol. Ther. 112, 744-760. doi:10.1016/j.pharmthera.2006.05.013

Ding, M., Wang, H., Qu, C., Xu, F., Zhu, Y., Lv, G.., et al. (2018). Pyrazolo[1,5-a] pyrimidine TRPC6 Antagonists for the Treatment of Gastric Cancer. Cancer Lett. 432, 47-55. doi:10.1016/j.canlet.2018.05.041

Ding, X., He, Z., Shi, Y., Wang, Q., and Wang, Y. (2010). Targeting TRPC6 Channels in Oesophageal Carcinoma Growth. Expert Opin. Ther. Targets 14, 513-527. doi:10.1517/14728221003733602

Doi, T., Shitara, K., Naito, Y., Shimomura, A., Fujiwara, Y., Yonemori, K., et al. (2017). Safety, Pharmacokinetics, and Antitumour Activity of Trastuzumab Deruxtecan (DS-8201), a HER2-Targeting Antibody-Drug Conjugate, in Patients with Advanced Breast and Gastric or Gastro-Oesophageal Tumours: a Phase 1 Dose-Escalation Study. Lancet Oncol. 18, 1512-1522. doi:10.1016/s1470-2045(17)30604-6

Dong, J., Aulestia, F. J., Assad Kahn, S., Zeniou, M., Dubois, L. G., El-Habr, E. A., et al. (2017). Bisacodyl and its Cytotoxic Activity on Human Glioblastoma Stem-like Cells. Implication of Inositol 1,4,5-triphosphate Receptor Dependent Calcium Signaling. Biochim. Biophys. Acta (Bba) - Mol. Cel Res. 1864, 1018-1027. doi:10.1016/j.bbamcr.2017.01.010

Dutton, S. J., Ferry, D. R., Blazeby, J. M., Abbas, H., Dahle-Smith, A., Mansoor, W., et al. (2014). Gefitinib for Oesophageal Cancer Progressing after Chemotherapy (COG): a Phase 3, Multicentre, Double-Blind, Placebo-Controlled Randomised Trial. Lancet Oncol. 15, 894-904. doi:10.1016/s1470-2045(14)70024-5

Engevik, K. A., Karns, R. A., Oshima, Y., and Montrose, M. H. (2020). Multiple Calcium Sources Are Required for Intracellular Calcium Mobilization during 
Gastric Organoid Epithelial Repair. Physiol. Rep. 8, e14384. doi:10.14814/phy2. 14384

Fatherazi, S., Presland, R. B., Belton, C. M., Goodwin, P., Al-Qutub, M., Trbic, Z., et al. (2007). Evidence that TRPC4 Supports the Calcium Selective ICRAC-like Current in Human Gingival Keratinocytes. Pflugers Arch.-Eur. J. Physiol. 453, 879-889. doi:10.1007/s00424-006-0156-4

Feske, S. (2011). Immunodeficiency Due to Defects in Store-Operated Calcium Entry. Ann. New York Acad. Sci. 1238, 74-90. doi:10.1111/j.1749-6632.2011. 06240.x

Fuchs, S., Rensing-Ehl, A., Speckmann, C., Bengsch, B., Schmitt-Graeff, A., Bondzio, I., et al. (2012). Antiviral and Regulatory T Cell Immunity in a Patient with Stromal Interaction Molecule 1 Deficiency. J. Immunol. 188, 1523-1533. doi:10.4049/jimmunol.1102507

Fujikuni, N., Yamamoto, H., Tanabe, K., Naito, Y., Sakamoto, N., Tanaka, Y., et al. (2014). Hypoxia-mediated CD24 Expression Is Correlated with Gastric Cancer Aggressiveness by Promoting Cell Migration and Invasion. Cancer Sci. 105, 1411-1420. doi:10.1111/cas.12522

Fukamachi, H., Seol, H. S., Shimada, S., Funasaka, C., Baba, K., Kim, J. H.., et al. (2013). CD49f(high) Cells Retain Sphere-Forming and Tumor-Initiating Activities in Human Gastric Tumors. PLoS One 8, e72438. doi:10.1371/ journal.pone. 0072438

Ge, P., Wei, L., Zhang, M., Hu, B., Wang, K., Li, Y., et al. (2018). TRPC1/3/6 Inhibition Attenuates the TGF-B1-Induced Epithelial-Mesenchymal Transition in Gastric Cancer via the Ras/Raf1/ERK Signaling Pathway. Cell Biol. Int. 42, 975-984. doi:10.1002/cbin.10963

Giannone, G., Rondé, P., Gaire, M., Haiech, J., and Takeda, K. (2002). Calcium Oscillations Trigger Focal Adhesion Disassembly in Human U87 Astrocytoma Cells. J. Biol. Chem. 277, 26364-26371. doi:10.1074/jbc.m203952200

Gualdani, R., de Clippele, M., Ratbi, I., Gailly, P., and Tajeddine, N. (2019). StoreOperated Calcium Entry Contributes to Cisplatin-Induced Cell Death in Nonsmall Cell Lung Carcinoma. Cancers. Mar. 26, 11.

Guilbert, A., Dhennin-Duthille, I., Hiani, Y. E., Haren, N., Khorsi, H., Sevestre, H., et al. (2008). Expression of TRPC6 Channels in Human Epithelial Breast Cancer Cells. BMC Cancer 8, 125. doi:10.1186/1471-2407-8-125

Hamburger, A., and Salmon, S. (1977). Primary Bioassay of Human Tumor Stem Cells. Science 197, 461-463. doi:10.1126/science.560061

He, L. P., Hewavitharana, T., Soboloff, J., Spassova, M. A., and Gill, D. L. (2005). A Functional Link between Store-Operated and TRPC Channels Revealed by the 3,5-bis(trifluoromethyl)pyrazole Derivative. Btp2. J. Biol. Chem. 280, 10997-11006. doi:10.1074/jbc.m411797200

Henson, D. E., Dittus, C., Younes, M., Nguyen, H., and Albores-Saavedra, J. (2004). Differential Trends in the Intestinal and Diffuse Types of Gastric Carcinoma in the United States, 1973-2000: Increase in the Signet Ring Cell Type. Arch. Pathol. Lab. Med. 128, 765-770. doi:10.5858/2004-128-765dtitia

Hong, J. H., Li, Q., Kim, M. S., Shin, D. M., Feske, S., Birnbaumer, L., et al. (2011). Polarized but Differential Localization and Recruitment of STIM1, Orail and TRPC Channels in Secretory Cells. Traffic 12, 232-245. doi:10.1111/j.16000854.2010.01138.x

Hsu, A., Chudasama, R., Almhanna, K., and Raufi, A. (2020). Targeted Therapies for Gastroesophageal Cancers. Ann. Transl Med. 8, 1104. doi:10.21037/atm-203265

Hu, Z., Cao, X., Fang, Y., Liu, G., Xie, C., Qian, K., et al. (2018). Transient Receptor Potential Vanilloid-type 2 Targeting on Stemness in Liver Cancer. Biomed. Pharmacother. 105, 697-706. doi:10.1016/j.biopha.2018.06.029

Huang, G. N., Zeng, W., Kim, J. Y., Yuan, J. P., Han, L., Muallem, S., et al. (2006). STIM1 Carboxyl-Terminus Activates Native SOC, Icrac and TRPC1 Channels. Nat. Cel Biol 8, 1003-1010. doi:10.1038/ncb1454

Huang, H. K., Lin, Y. H., Chang, H. A., Lai, Y. S., Chen, Y. C., Huang, S. C., et al. (2020). Chemoresistant Ovarian Cancer Enhances its Migration Abilities by Increasing Store-Operated $\mathrm{Ca}(2+)$ Entry-Mediated Turnover of Focal Adhesions. J. Biomed. Sci. 27, 36. doi:10.1186/s12929-020-00630-5

Jairaman, A., and Prakriya, M. (2013). Molecular Pharmacology of Store-Operated CRAC Channels. Channels 7, 402-414. doi:10.4161/chan.25292

Jardin, I., Diez-Bello, R., Lopez, J. J., Redondo, P. C., Salido, G. M., Smani, T., et al. (2018). TRPC6 Channels Are Required for Proliferation, Migration and Invasion of Breast Cancer Cell Lines by Modulation of Orail and Orai3 Surface Exposure. Cancers (Basel) 10, 331. doi:10.3390/cancers10090331
Jardin, I., Nieto, J., Salido, G. M., and Rosado, J. A. (2020). TRPC6 Channel and its Implications in Breast Cancer: an Overview. Biochim. Biophys. Acta (Bba) Mol. Cel Res. 1867, 118828. doi:10.1016/j.bbamcr.2020.118828

Jedrychowski, W., Wahrendorf, J., Popiela, T., and Rachtan, J. (1986). A CaseControl Study of Dietary Factors and Stomach Cancer Risk in Poland. Int. J. Cancer 37, 837-842. doi:10.1002/ijc.2910370607

Jemal, A., Bray, F., Center, M. M., Ferlay, J., Ward, E., and Forman, D. (2011). Global Cancer Statistics. CA: A Cancer J. Clinicians 61, 69-90. doi:10.3322/caac. 20107

Jiao, Q., Bi, L., Ren, Y., Song, S., Wang, Q., and Wang, Y. S. (2018). Advances in Studies of Tyrosine Kinase Inhibitors and Their Acquired Resistance. Mol. Cancer 17, 36. doi:10.1186/s12943-018-0801-5

Jin, J., Liao, Z., Zhang, Z., Ajani, J., Swisher, S., Chang, J. Y., et al. (2004). Induction Chemotherapy Improved Outcomes of Patients with Resectable Esophageal Cancer Who Received Chemoradiotherapy Followed by Surgery. Int. J. Radiat. Oncol. Biol. Phys. 60, 427-436. doi:10.1016/j. ijrobp.2004.03.033

Khan, H. Y., Mpilla, G. B., Sexton, R., Viswanadha, S., Penmetsa, K. V., Aboukameel, A., et al. (2020). Calcium Release-Activated Calcium (CRAC) Channel Inhibition Suppresses Pancreatic Ductal Adenocarcinoma Cell Proliferation and Patient-Derived Tumor Growth. Cancers (Basel) 12, 12. doi:10.3390/cancers 12030750

Kim, M. S., Hong, J. H., Li, Q., Shin, D. M., Abramowitz, J., Birnbaumer, L., et al. (2009). Deletion of TRPC3 in Mice Reduces Store-Operated Ca2+ Influx and the Severity of Acute Pancreatitis. Gastroenterology 137, 1509-1517. doi:10. 1053/j.gastro.2009.07.042

Kohn, E. C., Reed, E., Sarosy, G. A., Minasian, L., Bauer, K. S., Bostick-Bruton, F.., et al. (2001). A Phase I Trial of Carboxyamido-Triazole and Paclitaxel for Relapsed Solid Tumors: Potential Efficacy of the Combination and Demonstration of Pharmacokinetic Interaction. Clin. Cancer Res. 7, 1600-1609.

Kokoska, E. R., Smith, G. S., and Miller, T. A. (1998). Store-operated Calcium Influx in Human Gastric Cells: Role of Endogenous Prostaglandins. Surgery 124, 429-437. doi:10.1016/s0039-6060(98)70150-3

Kondratska, K., Kondratskyi, A., Yassine, M., Lemonnier, L., Lepage, G., Morabito, A., et al. (2014). Orail and STIM1 Mediate SOCE and Contribute to Apoptotic Resistance of Pancreatic Adenocarcinoma. Biochim. Biophys. Acta (Bba)-Mol. Cel Res. 1843, 2263-2269. doi:10.1016/j.bbamcr.2014.02.012

Kondratskyi, A., Yassine, M., Slomianny, C., Kondratska, K., Gordienko, D., Dewailly, E., et al. (2014). Identification of ML-9 as a Lysosomotropic Agent Targeting Autophagy and Cell Death. Cell Death Dis 5, e1193. doi:10.1038/ cddis.2014.156

Ku, G. Y., and Ilson, D. H. (2013). Emerging Tyrosine Kinase Inhibitors for Esophageal Cancer. Expert Opin. emerging Drugs 18, 219-230. doi:10.1517/ 14728214.2013.805203

Kurokawa, Y., Sugimoto, N., Miwa, H., Tsuda, M., Nishina, S., Okuda, H., et al. (2014). Phase II Study of Trastuzumab in Combination with S-1 Plus Cisplatin in HER2-Positive Gastric Cancer (HERBIS-1). Br. J. Cancer 110, 1163-1168. doi:10.1038/bjc.2014.18

Ladeiras-Lopes, R., Pereira, A. K., Nogueira, A., Pinheiro-Torres, T., Pinto, I., Santos-Pereira, R., et al. (2008). Smoking and Gastric Cancer: Systematic Review and Meta-Analysis of Cohort Studies. Cancer Causes Control 19, 689-701. doi:10.1007/s10552-008-9132-y

Lambert, R., and Hainaut, P. (2007). Esophageal Cancer: Cases and Causes (Part I). Endoscopy 39, 550-555. doi:10.1055/s-2007-966530

Lau, W. M., Teng, E., Chong, H. S., Lopez, K. A. P., Tay, A. Y. L., Salto-Tellez, M., et al. (2014). CD44v8-10 Is a Cancer-specific Marker for Gastric Cancer Stem Cells. Cancer Res. 74, 2630-2641. doi:10.1158/0008-5472.can-13-2309

Laurén, P. (1965). The Two Histological Main Types of Gastric Carcinoma: Diffuse and So-Called Intestinal-type Carcinoma. Acta Pathol. Microbiol. Scand. 64, 31-49. doi:10.1111/apm.1965.64.1.31

Le Deist, F., and Capiod, T. (2011). Immunodéficiences et pathologies associées aux mutations dans STIM/ORAI. Med. Sci. (Paris) 27, 737-745. doi:10.1051/ medsci/2011278016

Lee, S. H., Rigas, N. K., Lee, C. R., Bang, A., Srikanth, S., Gwack, Y., et al. (2016). Orail Promotes Tumor Progression by Enhancing Cancer Stemness via NFAT Signaling in Oral/oropharyngeal Squamous Cell Carcinoma. Oncotarget 7, 43239-43255. doi:10.18632/oncotarget.9755 
Lewis, R. S. (2003). Calcium Oscillations in T-Cells: Mechanisms and Consequences for Gene Expression. Biochem. Soc. Trans. 31, 925-929. doi:10.1042/bst0310925

Li, X., Lewis, M. T., Huang, J., Gutierrez, C., Osborne, C. K., Wu, M.-F., et al. (2008). Intrinsic Resistance of Tumorigenic Breast Cancer Cells to Chemotherapy. JNCI J. Natl. Cancer Inst. 100, 672-679. doi:10.1093/jnci/ $\operatorname{djn} 123$

Li, Y., Guo, B., Xie, Q., Ye, D., Zhang, D., Zhu, Y., et al. (2015). STIM1 Mediates Hypoxia-Driven Hepatocarcinogenesis via Interaction with HIF-1. Cel Rep. 12, 388-395. doi:10.1016/j.celrep.2015.06.033

Liu, B., Yu, H.-H., Ye, H.-L., Luo, Z.-Y., and Xiao, F. (2015). Effects of Stromal Interacting Molecule 1 Gene Silencing by Short Hairpin RNA on the Biological Behavior of Human Gastric Cancer Cells. Mol. Med. Rep. 12, 3047-3054. doi:10. 3892/mmr.2015.3778

Liu, G., Yuan, X., Zeng, Z., Tunici, P., Ng, H., Abdulkadir, I. R., et al. (2006). Analysis of Gene Expression and Chemoresistance of CD133+ Cancer Stem Cells in Glioblastoma. Mol. Cancer 5, 67. doi:10.1186/1476-4598-5-67

Liu, M., Inoue, K., Leng, T., Guo, S., and Xiong, Z.-G. (2014). TRPM7 Channels Regulate Glioma Stem Cell through STAT3 and Notch Signaling Pathways. Cell Signal. 26, 2773-2781. doi:10.1016/j.cellsig.2014.08.020

Liu, X., Singh, B. B., and Ambudkar, I. S. (2003). TRPC1 Is Required for Functional Store-Operated Ca2+ Channels. Role of Acidic Amino Acid Residues in the S5S6 Region. J. Biol. Chem. 278, 11337-11343. doi:10.1074/jbc.m213271200

Lordick, F., Kang, Y.-K., Chung, H.-C., Salman, P., Oh, S. C., Bodoky, G., et al. (2013). Capecitabine and Cisplatin with or without Cetuximab for Patients with Previously Untreated Advanced Gastric Cancer (EXPAND): a Randomised, Open-Label Phase 3 Trial. Lancet Oncol. 14, 490-499. doi:10.1016/s14702045(13)70102-5

Lu, H., Chen, I., Shimoda, L. A., Park, Y., Zhang, C., Tran, L., et al. (2017). Chemotherapy-Induced Ca2+ Release Stimulates Breast Cancer Stem Cell Enrichment. Cell Rep. 18, 1946-1957. doi:10.1016/j.celrep.2017.02.001

Luik, R. M., Wu, M. M., Buchanan, J., and Lewis, R. S. (2006). The Elementary Unit of Store-Operated Ca2+ Entry: Local Activation of CRAC Channels by STIM1 at ER-Plasma Membrane Junctions. J. Cell Biol. 174, 815-825. doi:10.1083/jcb. 200604015

Ma, J., and Pan, Z. (2003). Retrograde Activation of Store-Operated Calcium Channel. Cell Calcium 33, 375-384. doi:10.1016/s0143-4160(03)00050-2

Ma, X., Cheng, K.-T., Wong, C.-O., O’Neil, R. G., Birnbaumer, L., Ambudkar, I. S., et al. (2011). Heteromeric TRPV4-C1 Channels Contribute to Store-Operated Ca2+ Entry in Vascular Endothelial Cells. Cell calcium 50, 502-509. doi:10. 1016/j.ceca.2011.08.006

Marciel, M. P., Khadka, V. S., Deng, Y., Kilicaslan, P., Pham, A., Bertino, P.., et al. (2018). Selenoprotein K Deficiency Inhibits Melanoma by Reducing Calcium Flux Required for Tumor Growth and Metastasis. Oncotarget 2 (9), 13407-13422. doi:10.18632/oncotarget.24388

Maron, S. B., Xu, J., and Janjigian, Y. Y. (2020). Targeting EGFR in Esophagogastric Cancer. Front. Oncol. 10, 553876. doi:10.3389/fonc.2020.553876

Mercer, J. C., Dehaven, W. I., Smyth, J. T., Wedel, B., Boyles, R. R., Bird, G. S., et al. (2006). Large Store-Operated Calcium Selective Currents Due to Co-expression of Orail or Orai2 with the Intracellular Calcium Sensor. Stim1. J. Biol. Chem. 281, 24979-24990. doi:10.1074/jbc.m604589200

Mikoshiba, K., Furuichi, T., and Miyawaki, A. (1994). Structure and Function of IP3 Receptors. Semin. Cel. Biol. 5, 273-281. doi:10.1006/scel.1994.1033

Ming, X. Y., Fu, L., Zhang, L. Y., Qin, Y. R., Cao, T. T., Chan, K. W., et al. (2016). Integrin $\alpha 7$ Is a Functional Cancer Stem Cell Surface Marker in Oesophageal Squamous Cell Carcinoma. Nat. Commun. 7, 13568. doi:10.1038/ ncomms 13568

Mohiuddin, I. S., Wei, S. J., and Kang, M. H. (2020). Role of OCT4 in Cancer Stemlike Cells and Chemotherapy Resistance. Biochim. Biophys. Acta Mol. Basis Dis. 1866, 165432. doi:10.1016/j.bbadis.2019.03.005

Morelli, M. B., Nabissi, M., Amantini, C., Farfariello, V., Ricci-Vitiani, L., di Martino, S., et al. (2012). The Transient Receptor Potential Vanilloid-2 Cation Channel Impairs Glioblastoma Stem-like Cell Proliferation and Promotes Differentiation. Int. J. Cancer 131, E1067-E1077. doi:10.1002/ijc.27588

Morita, M., Kuwano, H., Ohno, S., Sugimachi, K., Seo, Y., Tomoda, H., et al. (1994). Multiple Occurrence of Carcinoma in the Upper Aerodigestive Tract Associated with Esophageal Cancer: Reference to Smoking, Drinking and Family History. Int. J. Cancer 58, 207-210. doi:10.1002/ijc.2910580211
Motiani, R. K., Hyzinski-García, M. C., Zhang, X., Henkel, M. M., Abdullaev, I. F., Kuo, Y.-H., et al. (2013). STIM1 and Orail Mediate CRAC Channel Activity and Are Essential for Human Glioblastoma Invasion. Pflugers Arch. - Eur. J. Physiol. 465, 1249-1260. doi:10.1007/s00424-013-1254-8

Nishikawa, S., Konno, M., Hamabe, A., Hasegawa, S., Kano, Y., Ohta, K., et al. (2013). Aldehyde Dehydrogenasehigh Gastric Cancer Stem Cells Are Resistant to Chemotherapy. Int. J. Oncol. 42, 1437-1442. doi:10.3892/ijo.2013.1837

Odiase, E., Zhang, X., Chang, Y., Nelson, M., Balaji, U., Gu, J., et al. (2021). In Esophageal Squamous Cells from Eosinophilic Esophagitis Patients, Th2 Cytokines Increase Eotaxin-3 Secretion through Effects on Intracellular Calcium and a Non-Gastric Proton Pump. Gastroenterology doi:10.1053/j. gastro.2021.02.016

Ohkuma, M., Haraguchi, N., Ishii, H., Mimori, K., Tanaka, F., Kim, H. M., et al. (2012). Absence of CD71 Transferrin Receptor Characterizes Human Gastric Adenosquamous Carcinoma Stem Cells. Ann. Surg. Oncol. 19, 1357-1364. doi:10.1245/s10434-011-1739-7

Ong, H. L., Cheng, K. T., Liu, X., Bandyopadhyay, B. C., Paria, B. C., Soboloff, J., et al. (2007). Dynamic Assembly of TRPC1-STIM1-Orai1 Ternary Complex Is Involved in Store-Operated Calcium Influx. Evidence for Similarities in StoreOperated and Calcium Release-Activated Calcium Channel Components. J. Biol. Chem. 282, 9105-9116. doi:10.1074/jbc.m608942200

Ong, H. L., and Ambudkar, I. S. (2015). Molecular Determinants of TRPC1 Regulation within ER-PM Junctions. Cell calcium 58, 376-386. doi:10.1016/j. ceca.2015.03.008

Pan, Z., Brotto, M., and Ma, J. (2014). Store-operated Ca2+entry in Muscle Physiology and Diseases. BMB Rep. 47, 69-79. doi:10.5483/bmbrep.2014.47. 2.015

Pan, Z., and Ma, J. (2015). Open Sesame: Treasure in Store-Operated Calcium Entry Pathway for Cancer Therapy. Sci. China Life Sci. 58, 48-53. doi:10.1007/ s11427-014-4774-3

Philipp, S., Trost, C., Warnat, J., Rautmann, J., Himmerkus, N., Schroth, G., et al. (2000). TRP4 (CCE1) Protein Is Part of Native Calcium Release-Activated Ca2+-like Channels in Adrenal Cells. J. Biol. Chem. 275, 23965-23972. doi:10. 1074/jbc.M003408200

Prevarskaya, N., Skryma, R., and Shuba, Y. (2018). Ion Channels in Cancer: Are Cancer Hallmarks Oncochannelopathies? Physiol. Rev. 98, 559-621. doi:10. 1152/physrev.00044.2016

Putney, J. W., Jr. (1986). A Model for Receptor-Regulated Calcium Entry. Cell Calcium 7, 1-12. doi:10.1016/0143-4160(86)90026-6

Ramos, S., Grigoryev, S., Rogers, E., Roos, J., Whitten, J., Stauderman, K., et al. (2012). CM3457, a Potent and Selective Oral CRAC Channel Inhibitor, Suppresses T and Mast Cell Function and Is Efficacious in Rat Models of Arthritis and Asthma (72.3). J. Immunol. 188, 72-73.

Rondé, P., Giannone, G., Gerasymova, I., Stoeckel, H., Takeda, K., and Haiech, J. (2000). Mechanism of Calcium Oscillations in Migrating Human Astrocytoma Cells. Biochim. Biophys. Acta (Bba)-Mol. Cell Res. 1498, 273-280. doi:10.1016/ s0167-4889(00)00102-6

Roos, J., DiGregorio, P. J., Yeromin, A. V., Ohlsen, K., Lioudyno, M., Zhang, S., et al. (2005). STIM1, an Essential and Conserved Component of Store-Operated Ca2+ Channel Function. J. Cel. Biol. 169, 435-445. doi:10.1083/jcb.200502019

Sakakura, C., Miyagawa, K., Fukuda, K., Shimomura, K., Takemura, M., Takagi, T., et al. (2003). [Possible Involvement of Inositol 1, 4, 5-trisphosphate Receptor Type 3 (IP3R3) in the Peritoneal Dissemination of Gastric Cancers]. Gan To Kagaku Ryoho 30, 1784-1787.

Sampath, B., and Sankaranarayanan, K. (2016). Glu106 Targeted Inhibitors of ORAI1 as Potential Ca2+ Release-Activated Ca2+ (CRAC) Channel Blockers Molecular Modeling and Docking Studies. J. Recept. Signal Transduct. Res. 36, 572-585. doi:10.3109/10799893.2016.1141956

Santulli, G., and Marks, A. (2015). Essential Roles of Intracellular Calcium Release Channels in Muscle, Brain, Metabolism, and Aging. Curr. Mol. Pharmacol. 8, 206-222. doi:10.2174/1874467208666150507105105

Schleifer, H., Doleschal, B., Lichtenegger, M., Oppenrieder, R., Derler, I., Frischauf, I., et al. (2012). Novel Pyrazole Compounds for Pharmacological Discrimination between Receptor-operated and Store-operated Ca 2+ Entry Pathways. Br. J. Pharmacol. 167, 1712-1722. doi:10.1111/j.1476-5381.2012. 02126.x

Schmidt, S., Liu, G., Liu, G., Yang, W., Honisch, S., Pantelakos, S., et al. (2014). Enhanced Orail and STIM1 Expression as Well as Store Operated Ca2+ Entry 
in Therapy Resistant Ovary Carcinoma Cells. Oncotarget 5, 4799-4810. doi:10. 18632/oncotarget.2035

Sehdev, A., and Catenacci, D. V. (2013). Gastroesophageal Cancer: Focus on Epidemiology, Classification, and Staging. Discov. Med. 16, 103-111.

Shaw, P. J., and Feske, S. (2012). Physiological and Pathophysiological Functions of SOCE in the Immune System. Front. Biosci. (Elite Ed) 4, 2253-2268. doi:10. 2741/540

Shi, Y., Ding, X., He, Z.-H., Zhou, K.-C., Wang, Q., and Wang, Y.-Z. (2009). Critical Role of TRPC6 Channels in G2 Phase Transition and the Development of Human Oesophageal Cancer. Gut 58, 1443-1450. doi:10.1136/gut.2009.181735

Siegel, R. L., Miller, K. D., and Jemal, A. (2017). Cancer Statistics, 2017. CA: A Cancer J. Clin. 67, 7-30. doi:10.3322/caac.21387

Soboloff, J., Spassova, M. A., Tang, X. D., Hewavitharana, T., Xu, W., and Gill, D. L. (2006). Orail and STIM Reconstitute Store-Operated Calcium Channel Function. J. Biol. Chem. 281, 20661-20665. doi:10.1074/jbc.c600126200

Spassova, M. A., Soboloff, J., He, L.-P., Xu, W., Dziadek, M. A., and Gill, D. L. (2006). STIM1 Has a Plasma Membrane Role in the Activation of StoreOperated Ca2+ Channels. Proc. Natl. Acad. Sci. 103, 4040-4045. doi:10.1073/ pnas. 0510050103

Spicer, J., Irshad, S., Ang, J. E., Enting, D., Kristeleit, R., Uttenreuther-Fischer, M., et al. (2017). A Phase I Study of Afatinib Combined with Paclitaxel and Bevacizumab in Patients with Advanced Solid Tumors. Cancer Chemother. Pharmacol. 79, 17-27. doi:10.1007/s00280-016-3189-1

Sundivakkam, P. C., Freichel, M., Singh, V., Yuan, J. P., Vogel, S. M., Flockerzi, V., et al. (2012). The Ca2+ Sensor Stromal Interaction Molecule 1 (STIM1) Is Necessary and Sufficient for the Store-Operated Ca2+ Entry Function of Transient Receptor Potential Canonical (TRPC) 1 and 4 Channels in Endothelial Cells. Mol. Pharmacol. 81, 510-526. doi:10.1124/mol.111. 074658

Sung, H., Ferlay, J., Siegel, R. L., Laversanne, M., Soerjomataram, I., Jemal, A., et al. (2021). Global Cancer Statistics 2020: GLOBOCAN Estimates of Incidence and Mortality Worldwide for 36 Cancers in 185 Countries. CA Cancer J. Clin. 0, 1-41. doi:10.3322/caac. 21660

Takaishi, S., Okumura, T., Tu, S., Wang, S. S. W., Shibata, W., Vigneshwaran, R., et al. (2009). Identification of Gastric Cancer Stem Cells Using the Cell Surface Marker CD44. Stem Cells 27, 1006-1020. doi:10.1002/stem.30

Takezawa, R., Cheng, H., Beck, A., Ishikawa, J., Launay, P., Kubota, H., et al. (2006). A Pyrazole Derivative Potently Inhibits Lymphocyte Ca2+ Influx and Cytokine Production by Facilitating Transient Receptor Potential Melastatin 4 Channel Activity. Mol. Pharmacol. 69, 1413-1420. doi:10.1124/mol.105.021154

Tang, B.-D., Xia, X., Lv, X.-F., Yu, B.-X., Yuan, J.-N., Mai, X.-Y., et al. (2017). Inhibition of Orail-Mediated Ca2+entry Enhances Chemosensitivity of HepG2 Hepatocarcinoma Cells to 5-fluorouracil. J. Cel. Mol. Med. 21, 904-915. doi:10. $1111 / \mathrm{jcmm} .13029$

Terashima, M., Kitada, K., Ochiai, A., Ichikawa, W., Kurahashi, I., Sakuramoto, S., et al. (2012). Impact of Expression of Human Epidermal Growth Factor Receptors EGFR and ERBB2 on Survival in Stage II/III Gastric Cancer. Clin. Cancer Res. 18, 5992-6000. doi:10.1158/1078-0432.ccr-12-1318

Tiruppathi, C., Ahmmed, G. U., Vogel, S. M., and Malik, A. B. (2006). Ca2+Signaling, TRP Channels, and Endothelial Permeability. Microcirculation 13, 693-708. doi:10.1080/10739680600930347

van Heijl, M., van Lanschot, J. J., Koppert, L. B., van Berge Henegouwen, M. I., Muller, K., Steyerberg, E. W., et al. (2008). Neoadjuvant Chemoradiation Followed by Surgery versus Surgery Alone for Patients with Adenocarcinoma or Squamous Cell Carcinoma of the Esophagus (CROSS). BMC Surg. 8, 21. doi:10.1186/1471-2482-8-21

Vaughan, T. L., Davis, S., Kristal, A., and Thomas, D. B. (1995). Obesity, Alcohol, and Tobacco as Risk Factors for Cancers of the Esophagus and Gastric Cardia: Adenocarcinoma versus Squamous Cell Carcinoma. Cancer Epidemiol. Biomarkers Prev. 4, 85-92.

Venkatachalam, K., and Montell, C. (2007). TRP Channels. Annu. Rev. Biochem. 76, 387-417. doi:10.1146/annurev.biochem.75.103004.142819

Verbsky, J. W., and Chatila, T. A. (2011). T-regulatory Cells in Primary Immune Deficiencies. Curr. Opin. Allergy Clin. Immunol. 11, 539-544. doi:10.1097/aci. 0b013e32834cb8fa

Vig, M., Beck, A., Billingsley, J. M., Lis, A., Parvez, S., Peinelt, C.., et al. (2006). CRACM1 Multimers Form the Ion-Selective Pore of the CRAC Channel. Curr. Biol. : CB 16, 2073-2079. doi:10.1016/j.cub.2006.08.085
Waddell, T., Chau, I., Cunningham, D., Gonzalez, D., Okines, A. F. C., Wotherspoon, A., et al. (2013). Epirubicin, Oxaliplatin, and Capecitabine with or without Panitumumab for Patients with Previously Untreated Advanced Oesophagogastric Cancer (REAL3): a Randomised, Open-Label Phase 3 Trial. Lancet Oncol. 14, 481-489. doi:10.1016/s14702045(13)70096-2

Waldron, R. T., Chen, Y., Pham, H., Go, A., Su, H. Y., Hu, C., et al. (2019). The Orai Ca 2+ Channel Inhibitor CM4620 Targets Both Parenchymal and Immune Cells to Reduce Inflammation in Experimental Acute Pancreatitis. J. Physiol. 597, 3085-3105. doi:10.1113/jp277856

Wang, J., Shimoda, L. A., and Sylvester, J. T. (2004). Capacitative Calcium Entry and TRPC Channel Proteins Are Expressed in Rat Distal Pulmonary Arterial Smooth Muscle. Am. J. Physiology-Lung Cell Mol. Physiol. 286, L848-L858. doi:10.1152/ajplung.00319.2003

Wang, J. Y., Sun, J., Huang, M. Y., Wang, Y. S., Hou, M. F., Sun, Y.., et al. (2015). STIM1 Overexpression Promotes Colorectal Cancer Progression, Cell Motility and COX-2 Expression. Oncogene 34, 4358-4367. doi:10.1038/onc.2014.366

Wang, L., Hao, J., Zhang, Y., Yang, Z., Cao, Y., Lu, W., et al. (2017a). Orai1 Mediates Tumor-Promoting Store-Operated $\mathrm{Ca}(2+)$ Entry in Human Gastrointestinal Stromal Tumors via C-KIT and the Extracellular SignalRegulated Kinase Pathway. Tumour Biol. 39, 1010428317691426. doi:10. $1177 / 1010428317691426$

Wang, V. E., Grandis, J. R., and Ko, A. H. (2016). New Strategies in Esophageal Carcinoma: Translational Insights from Signaling Pathways and Immune Checkpoints. Clin. Cancer Res. 22, 4283-4290. doi:10.1158/1078-0432.ccr16-0292

Wang, Y., Zhang, C., Zhu, H., Tang, J., Zhang, S., Luo, J., et al. (2017b). CD90 Positive Cells Exhibit Aggressive Radioresistance in Esophageal Squamous Cell Carcinoma. J. Thorac. Dis. 9, 610-620. doi:10.21037/jtd.2017.03.28

Warren, J. R., Marshall, B., and Marshall, B. (1983). Unidentified Curved Bacilli on Gastric Epithelium in Active Chronic Gastritis. Lancet 1, 1273-1275.

Wenqi, D., Li, W., Shanshan, C., Bei, C., Yafei, Z., Feihu, B., et al. (2009). EpCAM Is Overexpressed in Gastric Cancer and its Downregulation Suppresses Proliferation of Gastric Cancer. J. Cancer Res. Clin. Oncol. 135, 1277-1285. doi:10.1007/s00432-009-0569-5

Wheeler, J. B., and Reed, C. E. (2012). Epidemiology of Esophageal Cancer. Surg. Clin. North America 92, 1077-1087. doi:10.1016/j.suc.2012.07.008

Wilke, H., Muro, K., Van Cutsem, E., Oh, S.-C., Bodoky, G., Shimada, Y., et al. (2014). Ramucirumab Plus Paclitaxel versus Placebo Plus Paclitaxel in Patients with Previously Treated Advanced Gastric or Gastro-Oesophageal Junction Adenocarcinoma (RAINBOW): a Double-Blind, Randomised Phase 3 Trial. Lancet Oncol. 15, 1224-1235. doi:10.1016/s1470-2045(14)70420-6

Wong, J. H., Ho, K. H., Nam, S., Hsu, W. L., Lin, C. H., Chang, C. M., et al. (2017). Store-operated $\mathrm{Ca}(2+)$ Entry Facilitates the Lipopolysaccharide-Induced Cyclooxygenase-2 Expression in Gastric Cancer Cells. Scientific Rep. 7, 12813. doi:10.1038/s41598-017-12648-1

Xia, J., Wang, H., Huang, H., Sun, L., Dong, S., Huang, N., et al. (2016). Elevated Orail and STIM1 Expressions Upregulate MACC1 Expression to Promote Tumor Cell Proliferation, Metabolism, Migration, and Invasion in Human Gastric Cancer. Cancer Lett. 381, 31-40. doi:10.1016/j.canlet.2016.07.014

Xu, J.-M., Zhou, Y., Gao, L., Zhou, S.-X., Liu, W.-H., and Li, X.-A. (2016). Stromal Interaction Molecule 1 Plays an Important Role in Gastric Cancer Progression. Oncol. Rep. 35, 3496-3504. doi:10.3892/or.2016.4704

Xue, Z., Yan, H., Li, J., Liang, S., Cai, X., Chen, X., et al. (2012). Identification of Cancer Stem Cells in Vincristine Preconditioned SGC7901 Gastric Cancer Cell Line. J. Cell Biochem. 113, 302-312. doi:10.1002/jcb.23356

Yamashita, M., Somasundaram, A., and Prakriya, M. (2011). Competitive Modulation of Ca2+ Release-Activated Ca2+ Channel Gating by STIM1 and 2-Aminoethyldiphenyl Borate. J. Biol. Chem. 286, 9429-9442. doi:10.1074/jbc. m110.189035

Yang, H., Mergler, S., Sun, X., Wang, Z., Lu, L., Bonanno, J. A., et al. (2005). TRPC4 Knockdown Suppresses Epidermal Growth Factor-Induced Store-Operated Channel Activation and Growth in Human Corneal Epithelial Cells. J. Biol. Chem. 280, 32230-32237. doi:10.1074/jbc.m504553200

Yang, N., Tang, Y., Wang, F., Zhang, H., Xu, D., Shen, Y., et al. (2013). Blockade of Store-Operated $\mathrm{Ca}(2+)$ Entry Inhibits Hepatocarcinoma Cell Migration and Invasion by Regulating Focal Adhesion Turnover. Cancer Lett. 330, 163-169. doi:10.1016/j.canlet.2012.11.040 
Yang, S., Zhang, J. J., and Huang, X.-Y. (2009). Orail and STIM1 Are Critical for Breast Tumor Cell Migration and Metastasis. Cancer cell 15, 124-134. doi:10. 1016/j.ccr.2008.12.019

Yang, Y. M., Hong, P., Xu, W. W., He, Q. Y., and Li, B. (2020). Advances in Targeted Therapy for Esophageal Cancer. Signal Transduct. Target Ther. 5, 229. doi:10.1038/s41392-020-00323-3

Yano, S., Kondo, K., Yamaguchi, M., Richmond, G., Hutchison, M., Wakeling, A., et al. (2003). Distribution and Function of EGFR in Human Tissue and the Effect of EGFR Tyrosine Kinase Inhibition. Anticancer Res. 23, 3639-3650.

Yeromin, A. V., Zhang, S. L., Jiang, W., Yu, Y., Safrina, O., and Cahalan, M. D. (2006). Molecular Identification of the CRAC Channel by Altered Ion Selectivity in a Mutant of Orai. Nature 443, 226-229. doi:10.1038/ nature 05108

Yoshino, T., Ishikawa, J., Ohga, K., Morokata, T., Takezawa, R., Morio, H., et al. (2007). YM-58483, a Selective CRAC Channel Inhibitor, Prevents AntigenInduced Airway Eosinophilia and Late Phase Asthmatic Responses via Th2 Cytokine Inhibition in Animal Models. Eur. J. Pharmacol. 560, 225-233. doi:10. 1016/j.ejphar.2007.01.012

Yu, J., Wang, S., Zhao, W., Duan, J., Wang, Z., Chen, H., et al. (2018). Mechanistic Exploration of Cancer Stem Cell Marker Voltage-Dependent Calcium Channel a2 $\delta 1$ Subunit-Mediated Chemotherapy Resistance in Small-Cell Lung Cancer. Clin. Cancer Res. 24, 2148-2158. doi:10.1158/1078-0432.ccr-17-1932

Zhang, S. L., Yu, Y., Roos, J., Kozak, J. A., Deerinck, T. J., Ellisman, M. H., et al. (2005). STIM1 Is a Ca2+ Sensor that Activates CRAC Channels and Migrates from the Ca2+ Store to the Plasma Membrane. Nature 437, 902-905. doi:10. 1038/nature04147

Zhang, S., Remillard, C. V., Fantozzi, I., and Yuan, J. X.-J. (2004). ATP-induced Mitogenesis Is Mediated by Cyclic AMP Response Element-Binding ProteinEnhanced TRPC4 Expression and Activity in Human Pulmonary Artery Smooth Muscle Cells. Am. J. Physiology-Cell Physiol. 287, C1192-C1201. doi:10.1152/ajpcell.00158.2004

Zhang, S. S., Wen, J., Yang, F., Cai, X. L., Yang, H., Luo, K. J.., et al. (2013). High Expression of Transient Potential Receptor C6 Correlated with Poor Prognosis in Patients with Esophageal Squamous Cell Carcinoma. Med. Oncol. 30, 607. doi:10.1007/s12032-013-0607-7
Zhang, X., and Pan, Z. (2020). Influence of Microbiota on Immunity and Immunotherapy for Gastric and Esophageal Cancers. Gastroenterol. Rep. 8, 206-214. doi:10.1093/gastro/goaa014

Zhang, Y., Cruickshanks, N., Yuan, F., Wang, B., Pahuski, M., Wulfkuhle, J., et al. (2017). Targetable T-type Calcium Channels Drive Glioblastoma. Cancer Res. 77, 3479-3490. doi:10.1158/0008-5472.can-16-2347

Zhao, W., Wang, L., Han, H., Jin, K., Lin, N., Guo, T., et al. (2013). 1B50-1, a mAb Raised against Recurrent Tumor Cells, Targets Liver Tumor-Initiating Cells by Binding to the Calcium Channel a2 $\delta 1$ Subunit. Cancer cell 23, 541-556. doi:10.1016/j.ccr.2013.02.025

Zheng, H. C. (2017). The Molecular Mechanisms of Chemoresistance in Cancers Oncotarget 8, 59950-59964. doi:10.18632/oncotarget.19048

Zhu, H., Zhang, H., Jin, F., Fang, M., Huang, M., Yang, C. S., et al. (2014a). Elevated Orail Expression Mediates Tumor-Promoting Intracellular Ca2+ Oscillations in Human Esophageal Squamous Cell Carcinoma. Oncotarget 5, 3455-3471. doi:10.18632/oncotarget.1903

Zhu, M., Wang, H., Cui, J., Li, W., An, G., Pan, Y., et al. (2017). Calcium-binding Protein S100A14 Induces Differentiation and Suppresses Metastasis in Gastric Cancer. Cell Death Dis. 8, e2938. doi:10.1038/cddis.2017.297

Zhu, X., Chu, P. B., Peyton, M., and Birnbaumer, L. (1995). Molecular Cloning of a Widely Expressed Human Homologue for the Drosophila Trp Gene. FEBS Lett. 373, 193-198. doi:10.1016/0014-5793(95)01038-g

Zhu, Y., Yu, J., Wang, S., Lu, R., Wu, J., and Jiang, B. (2014b). Overexpression of CD133 Enhances Chemoresistance to 5-fluorouracil by Activating the PI3K/ Akt/p70S6K Pathway in Gastric Cancer Cells. Oncol. Rep. 32, 2437-2444. doi:10.3892/or.2014.3488

Conflict of Interest: The authors declare that the research was conducted in the absence of any commercial or financial relationships that could be construed as a potential conflict of interest.

Copyright (C) 2021 Chang, Roy and Pan. This is an open-access article distributed under the terms of the Creative Commons Attribution License (CC BY). The use, distribution or reproduction in other forums is permitted, provided the original author(s) and the copyright owner(s) are credited and that the original publication in this journal is cited, in accordance with accepted academic practice. No use, distribution or reproduction is permitted which does not comply with these terms. 